\title{
Characterization of the Pore Filling of Solid State Dye Sensitized Solar Cells with Photoinduced Absorption Spectroscopy
}

\author{
Carol Olson, Dirk Veldman, Klaas Bakker, and Frank Lenzmann \\ Solar Energy, Energy Research Centre of the Netherlands (ECN), Westerduinweg 3, 1755 LE Petten, The Netherlands \\ Correspondence should be addressed to Carol Olson, olson@ecn.nl
}

Received 15 October 2010; Revised 26 April 2011; Accepted 16 May 2011

Academic Editor: Dinko Chakarov

Copyright () 2011 Carol Olson et al. This is an open access article distributed under the Creative Commons Attribution License, which permits unrestricted use, distribution, and reproduction in any medium, provided the original work is properly cited.

\begin{abstract}
Near steady-state photoinduced absorption (PIA) and UV-Vis absorption spectroscopy are used to characterize the pore filling of spiro-MeOTAD (2, 2',7,7'-tetrakis-( $N, N$-di- $p$-methoxyphenylamine $) 9,9^{\prime}$-spirobifluorene) into the nanoparticulate $\mathrm{TiO}_{2}$ electrode of a solid-state dye-sensitized solar cell (ssDSC). The volumetric ratio of filled to unfilled pore volumes, as well as the optical signature of interacting chemical species, that is, the hole-transfer yield (HTY), are investigated. PIA spectroscopy is used to measure the HTY, relative to the amount of spiro-MeOTAD present, without needing to determine the extinction coefficients of the dye and spiro-MeOTAD cation species. The Beer-Lambert law is used to relate the relative PIA signal to the penetration length of the hole-conductor in the $\mathrm{TiO}_{2}$ film. For the sample thickness range of $1.4-5 \mu \mathrm{m}$ investigated here, the optimum characteristic penetration length is determined to be $3.1+0.46 \mu \mathrm{m}$, which is compared to $1.4 \mu \mathrm{m}$ for the $200 \mathrm{mg} \mathrm{mL}^{-1}$ concentration of spiroMeOTAD conventionally used. Therefore, doubling the effective penetration of spiro-MeOTAD is necessary to functionalize all the dye molecules in a ssDSC.
\end{abstract}

\section{Introduction}

First generation dye sensitized solar cells (DSCs) are composed of a high surface area nanoparticulate $\mathrm{TiO}_{2}$ electrode, onto which a ruthenium dye, such as the Z907 dye (cis-RuLL' $(\mathrm{SCN})_{2} \quad\left(\mathrm{~L}=4,4^{\prime}\right.$-dicarboxylic acid$2,2^{\prime}$-bipyridine, $\mathrm{L}^{\prime}=4,4^{\prime}$-dinonyl-2,2'-bipyridine), $[1,2]$ is adsorbed, immersed in a liquid electrolyte, typically containing an $\mathrm{I}^{-} / \mathrm{I}_{3}^{-}$redox couple, which conducts holes to a platinum counter electrode [3]. In the next generation of dye cells, however, replacement of the liquid electrolyte with a solid electrolyte is desirable. The liquid electrolyte presents sealing and module production challenges, especially because the $\mathrm{I}^{-} / \mathrm{I}_{3}^{-}$redox couple is corrosive to metals such as $\mathrm{Ag}$, the grid metal, and degradation products from the electrolyte block the activity of the Pt cathode [4]. The most widely investigated and successful [5] solid-state electrolyte material to date is the molecular hole-transporting spiro-MeOTAD [6, 7] but other possibilities for iodine-free electrolytes [8], including inorganic and polymeric holetransporting materials, have also been investigated.

The infiltration of a solid into a nanoporous electrode emerged as a challenging problem from the start $[6,7]$ and has remained [9-11] so in the making of ssDSCs. The primary characterization tool to date has been scanning electron microscopy (SEM) [10]. In the best cases, SEM images roughly indicate the homogeneity of the spiro$\mathrm{MeOTAD} / \mathrm{TiO}_{2}$ composite at the exposed surface. Unlike transient absorption spectroscopy (TAS), it cannot quantitatively measure the percentage of dye molecules that are in effective contact with the hole transporter and therefore are regenerated, that is, the hole transfer yield (HTY). TAS optically identifies the signal of an oxidized species and quantifies it by use of the extinction coefficient.

TAS has been used to observe the kinetics of various electron transfer processes in the DSC [12-14] and to compare the HTY of various hole-conducting materials to spiro-MeOTAD [15]. However, it has not been possible 
to isolate the separate absorption contributions from the charged dye and the spiro-MeOTAD in an assembled ssDSC within the spectral range of $500-1000 \mathrm{~nm}$ [16]. By comparing TAS results of both sides of a ssDSC sample, a concentration gradient in the filling of the spiro-MeOTAD is generally not observed, except for very low concentrations of spiro-MeOTAD or very thick $\mathrm{TiO}_{2}$ films $[15,17,18]$. The strong absorption of the oxidized spiro-MeOTAD was unambiguously identified in the IR region, when TAS measurements were taken between 600-1500 nm [18].

Snaith et al. [18] proposed that the amount of spiroMeOTAD in the pores of the $\mathrm{TiO}_{2}$ is equal to the concentration of spiro-MeOTAD of the starting solution, $c$, plus an amount from the wet overlayer, resulting from the spincoating, which is driven into the film by a concentration gradient setup during the process of evaporation. They defined a "filling fraction", $F$, as the ratio of the thickness of the spiro-MeOTAD, $t_{\text {spiro }}$, divided by the equivalent thickness of the pores, equation $(1 \mathrm{a})$, where $t_{\text {spiro }}$ depends on the the thickness of the wet overlayer of spiro-MeOTAD solution, $t_{\mathrm{WET}}$, the final dry spiro-MeOTAD "overlayer" thickness, $t_{\mathrm{OL}}$, the thickness of the $\mathrm{TiO}_{2}$ film, $t_{\mathrm{TiO}_{2}}$, and the porosity of the titania, $p,(1 \mathrm{~b})$

$$
\begin{gathered}
F=\frac{t_{\text {spiro }}}{\left(p * t_{\mathrm{TiO}_{2}}\right)}, \\
t_{\text {spiro }}=c^{*}\left(t_{\mathrm{WET}}+\left(p * t_{\mathrm{TiO}_{2}}\right)\right)-t_{\mathrm{OL}}
\end{gathered}
$$

$T_{\text {WET }}$ is determined by spin-coating various concentrations of the spiro-MeOTAD onto flat substrates. After drying, the film thicknesses were measured with the SEM and the volume of the dry spiro-MeOTAD film was calculated. The wet volume results from dividing the dry volume of the spiroMeOTAD by the $\%$ volume that the spiro-MeOTAD occupies in the starting solution (calculated from the density and the starting concentration). The focus is on the change in spun wet film thickness due to the change in solute concentration, which has been observed for many solutes and solvents [16]. Solvation effects are not considered here. Ding et al. [19] tested (1a) and (1b) with various characterization techniques, and they were the first to largely validate Snaith's equation by quantifying the spiro-MeOTAD, desorbed out of the ssDSC, with UV-Vis absorption measurements.

In this work, we analyze the volume-based filling fraction by comparing calculated and experimental spiro-MeOTAD sample masses. From this analysis, an empirical correction factor is proposed to bring the filling fraction to more closely reflect the actual mass infiltrated into the pores. Observation of the filling fraction is complementary to the information gained with TAS, that is, the fraction of dye molecules that are (not) being regenerated by the spiro-MeOTAD.

We propose a method of using photoinduced absorption spectroscopy (PIA) to relatively determine the dye regeneration yield of an ssDSC, and we show its relationship to the filling fraction. After identifying the separate spectral contribution of the oxidized solid spiro-MeOTAD in a blend with phenyl-C71-butyric-acid-methyl ester ([70]PCBM) on $\mathrm{TiO} 2$, we examine the PIA spectra of ssDSCs with various filling fractions. We demonstrate that a single PIA measurement of a ssDSC at two different wavelengths can be used as a relative measure for the dye regeneration yield.

\section{Experimental}

2.1. Sample Preparation. The $\mathrm{SnO}_{2}: \mathrm{F}$ coated glass substrates were cleaned with Extran MAO1, sodium hydroxide solution and ethanol and sintered at $450^{\circ} \mathrm{C}$ for 1 hour. The substrates were then coated with a compact layer of $\mathrm{TiO}_{2}$ by aerosol spray pyrolysis deposition, at 0.9 bar and $\sim 470^{\circ} \mathrm{C}$, of titanium (IV) isopropoxide (1.56g, Aldrich 97\%), acetyl acetone $(2.3 \mathrm{~g})$, and ethanol $(113.3 \mathrm{~g})$. A total of 5 layers produced $80-100 \mathrm{~nm}$ of flat compact $\mathrm{TiO}_{2}$ after sintering at $570^{\circ} \mathrm{C}$ for $30 \mathrm{~min} . \mathrm{TiO}_{2}$ paste (Dyesol screenprint paste DSR 18R-T, $3 \mathrm{~g})$ was diluted with ethanol $(3 \mathrm{~mL})$ for 4 micron thick films this paste was further diluted with ethanol for thinner films, and was doctor bladed onto the substrates. They were then dried $\left(20 \mathrm{~min}\right.$ at $\left.80^{\circ} \mathrm{C}\right)$ and sintered at a rate of $900^{\circ} \mathrm{C} / \mathrm{h}$ until $450^{\circ} \mathrm{C}$ where they remained for 30 minutes. After the substrates were cooled down to approximately $40^{\circ} \mathrm{C}$ they were immersed in aqueous $\mathrm{TiCl}_{4}$ solution $(40 \mathrm{mM})$, kept at $70^{\circ} \mathrm{C}$ for $30 \mathrm{~min}$, and subsequently rinsed with deionized water and ethanol. They were sintered again at $450^{\circ} \mathrm{C}$ for 30 minutes. Directly out of the oven, the $\mathrm{TiO}_{2}$ films were sensitized overnight in a solution of Z907 Dyesol DNH2 (0.28 mM) in a 1:1 mixture of $\mathrm{CH}_{4} \mathrm{CN}$ : $\mathrm{tBuOH}$, and subsequently rinsed with $\mathrm{CH}_{4} \mathrm{CN}$. The spiro-MeOTAD solution (Merck SHT-263) was dissolved overnight at $70^{\circ} \mathrm{C}$ in chlorobenzene at concentrations of $25,45,90,100,180$, and $200 \mathrm{mg} \mathrm{mL}^{-1}$. Before spin-coating, TBP $(0.1 \mu \mathrm{L}$ per mg spiro-MeOTAD) and Li-FSI solution $(175 \mathrm{mg} / \mathrm{mL} \mathrm{Li}-\mathrm{FSI}$ in Acetonitrile; $0.21 \mu \mathrm{L}$ per mg spiroMeOTAD) was added to this solution. The solution was heated again to $70^{\circ} \mathrm{C}$ and then was spin-coated $(180 \mu \mathrm{L}$ or $20 \mu \mathrm{L} / \mathrm{cm}^{2}$ ) onto the $\mathrm{TiO}_{2}$ films that had been heated on a hotplate for 90 seconds at $70^{\circ} \mathrm{C}$. Spin-coating was done with a Laurell Technologies Corp. spin coater (Model WS400B-6NPP/LITE) programmed to wait 1 minute, accelerate to $2300 \mathrm{rpm}$ for $30 \mathrm{sec}$, and decelerate to $800 \mathrm{rpm}$ for 30 seconds. After the spiro-MeOTAD was applied, $100 \mathrm{~nm}$ thick gold contacts were thermally evaporated on top of the spiro$\mathrm{MeOTAD}$ overlayer with a rate of $0.15 \mathrm{~nm} / \mathrm{s}$ at a pressure of $1 \times 10^{-6}$ mbar.

The spectra of the dye alone was obtained from a $\mathrm{TiO}_{2}$ film sensitized with Z907 dye as described above but without spin-coating and gold evaporation.

The sample with a blend of [70]PCBM and spiroMeOTAD on $\mathrm{TiO}_{2}$ was made using [70]PCBM ([6,6]phenyl C71-butyric acid methyl ester, Solenne B.V., used as received, $6.9 \mathrm{~g}$ ) and dissolved at $70^{\circ} \mathrm{C}$ in chlorobenzene $(100 \mu \mathrm{L})$. After the [70]PCBM was fully dissolved, a solution ( $100 \mu \mathrm{L}$ of $180 \mathrm{mg} \mathrm{mL}^{-1}$ spiro-MeOTAD in chlorobenzene) was added. This [70]PCBM/spiro solution was then spincoated as described above on a TCO substrate coated with $80 \mathrm{~nm}$ of compact $\mathrm{TiO}_{2}$.

The total thickness $\left(\mathrm{TiO}_{2}+\right.$ spiro MeOTAD overlayer) of the ssDSC was measured using a Dektak Profiler after 
a scratch with a scalpel was made in the nonactive region between the gold contacts.

2.2. IV Measurements. Current-voltage measurements of the ssDSC were performed using a continuous solar simulator (Wacom) with a $5 \mathrm{~kW}$ Xe lamp (Type WXS-300S-50). The measurements were performed at STC (Standard Test Conditions: $1000 \mathrm{~W} \mathrm{~m}^{-2}, 25^{\circ} \mathrm{C}$ and AM1.5 spectrum, inclusive of a spectral mismatch correction, designed for the liquid DSC with Z907, utilizing a monocrystalline silicon solar cell with KG3 filter (Fraunhofer ISE RS-ID 2)) using a home-made measurement system which included a Keithley 2400 Source meter. The mismatch factor was not tailored to the ssDSC. Our experience with Z907 informs us of an error of about $5 \%$.

2.3. Desorption Measurements. UV-Vis spectra were taken using a HP 8453 spectrometer and cuvettes from Hellma type 117.100-QS. The area of the cut samples was determined with the aid of a computerized optical microscope (Leica MZ7.5 Microsystems). Desorption of the samples was done in a closed flask filled with a known volume of chlorobenzene for 1 hour.

2.4. Density of Spiro-MeOTAD. A quartz cuvette with an opening of $4 \times 10 \mathrm{~mm}$ was filled to the rim with water to determine the total inner volume of the cuvette. The volume was calculated by subtracting the weight of the full cuvette with that of the empty cuvette. To determine the volume of spiro-MeOTAD, this procedure was done on both an empty cuvette and a cuvette containing spiro-MeOTAD. After the volume of the empty cuvette was determined, the cuvette was filled with a $200 \mathrm{mg} / \mathrm{mL}$ spiro solution and heated to $70^{\circ} \mathrm{C}$ for 24 hours to evaporate the chlorobenzene. The weight of the spiro-MeOTAD was then determined by subtracting the weight of the cuvette before and after it was filled with spiro MeOTAD.

2.5. Photoinduced Absorption. Near steady-state photoinduced absorption spectra were recorded between 0.5 and $2.5 \mathrm{eV}$ by excitation at $458(2.71 \mathrm{eV})$ or $514 \mathrm{~nm}(2.41 \mathrm{eV})$ with a mechanically modulated $(275 \mathrm{~Hz})$ continuous wave argon ion laser pump beam and by measuring the change in transmission of a tungsten-halogen probe beam through the sample $(\Delta T)$ with a phase sensitive lock-in amplifier after dispersion with a monochromator and detection using Si, InGaAs, and cooled InSb detectors. The pump power was typically $50 \mathrm{~mW}$ with a beam diameter of $2 \mathrm{~mm}$. The signal intensity $\left(\Delta T T^{-1}\right)$ was corrected for the photoluminescence, which was recorded in a separate experiment. Samples were measured in ambient atmosphere $(290 \mathrm{~K})$. The error is estimated to be $<5 \%$, but depends on the signal intensity and the transmission of the sample. Any error in the overlap of the beams is cancelled out by dividing the signals taken at different wavelengths.

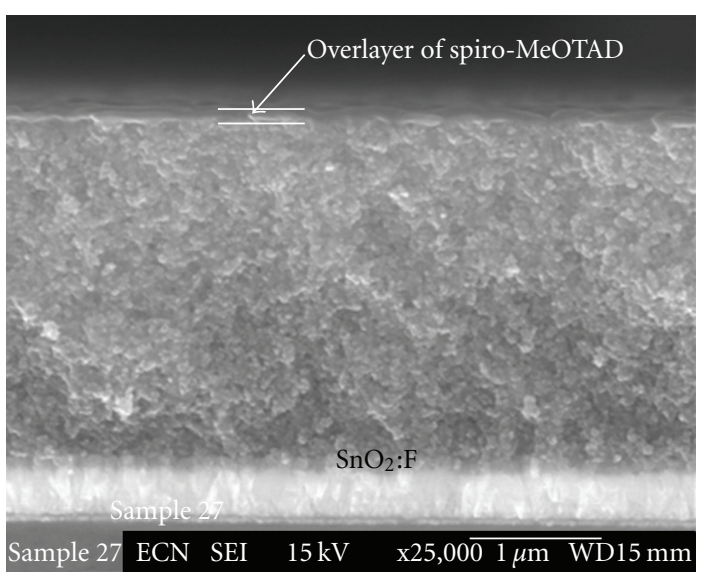

FIGURE 1: SEM cross-section of a ssDSC: the overlayer of the spiroMeOTAD is visible on the top of the $\mathrm{TiO}_{2}$ film.

\section{Results and Discussion}

3.1. SEM Characterization and Filling Fraction Analysis. A typical example of an ssDSC cross-section is shown in Figure 1. The $\mathrm{SnO}_{2}: \mathrm{F}$ layer on the conducting glass is clearly visible. The degree of the penetration of the spiroMeOTAD into the $\mathrm{TiO}_{2}$ is visually often not apparent and the composite often appears as a monolithic layer. The spiro$\mathrm{MeOTAD}$ overlayer however is evident and measurable in the SEM image. ssDSC cross-sections showing a range of overlayer thicknesses are shown in Figure 2. The images $\mathrm{A}$ and $\mathrm{B}$ in Figure 2 have relatively thick spiro-MeOTAD overlayers, with visible striations apparently produced in the spin-coating process step. While the upper edge in Image C of Figure 2 is smooth, it is not resolvable whether there is a continuous spiro-MeOTAD overlayer or not. The existence of this layer was only deduced by the electrical measurements described below. The topmost edge of the sample in Image D appears to have a rougher surface, with particles clearly visible, indicating that there is no overlayer present, or that the overlayer may be shortened by the particles sticking up.

In order to calculate the filling fraction in (1a) and (1b), the thicknesses of the spiro-MeOTAD overlayer and of the $\mathrm{TiO}_{2}$ film were measured by SEM. The porosity was taken to be $68 \%$ [19], which is typical for unsensitized $\mathrm{TiO}_{2}$ films. The influences on the porosity due to sample variation, the presence of the dye, double layer or solvation effects, were not taken into account here. The focus is to identify the influential parameters and the trends observed in the pore filling due to the variation of spiro-MeOTAD concentration. Figure 3 shows the range of filling fractions, as calculated using (1a) and (1b), plotted as a function of the concentration of spiro-MeOTAD in solution, for the ssDSC samples in this study. The relationship of $t_{\mathrm{WET}}$ to the spiroMeOTAD concentration is plotted in Figure 4(a).

3.2. I-V Characteristics. The short circuit currents and fill factors are plotted in Figure 4(b) for some samples with spiro-MeOTAD concentrations of 100 and $200 \mathrm{mg} \mathrm{mL}^{-1}$. Cells having no overlayer (as for all samples with 


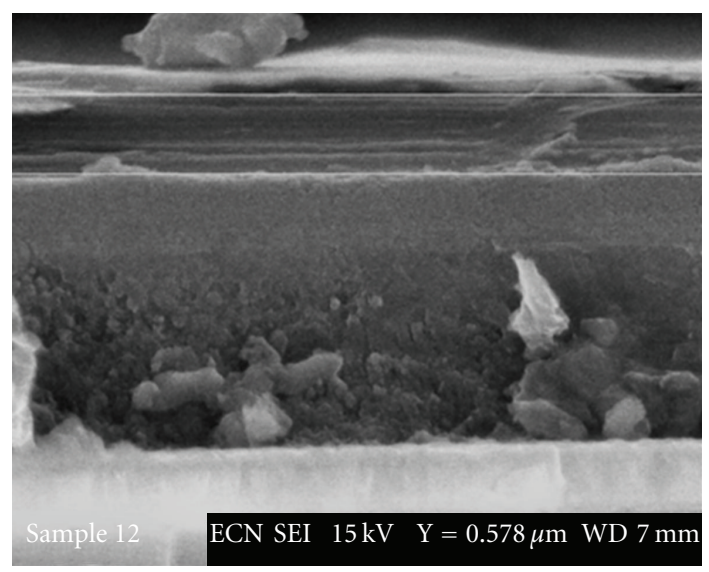

(a)

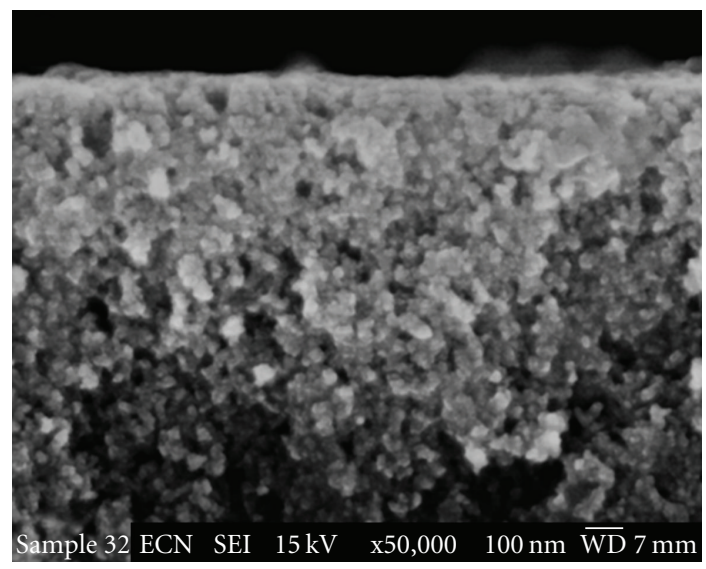

(c)

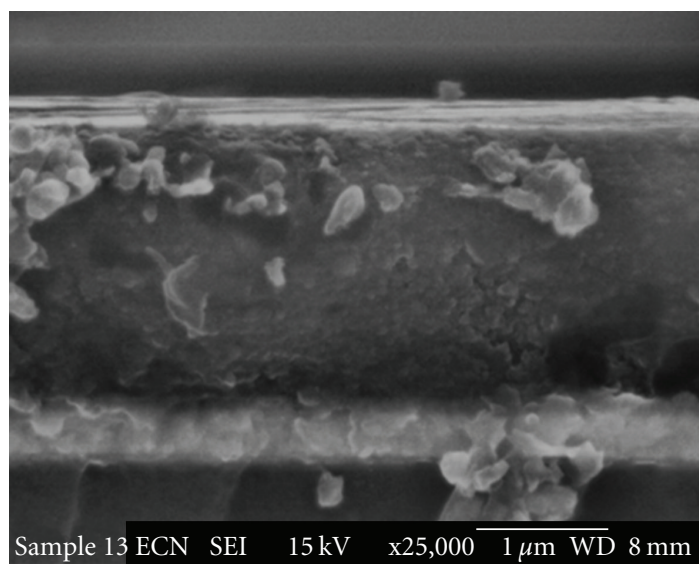

(b)

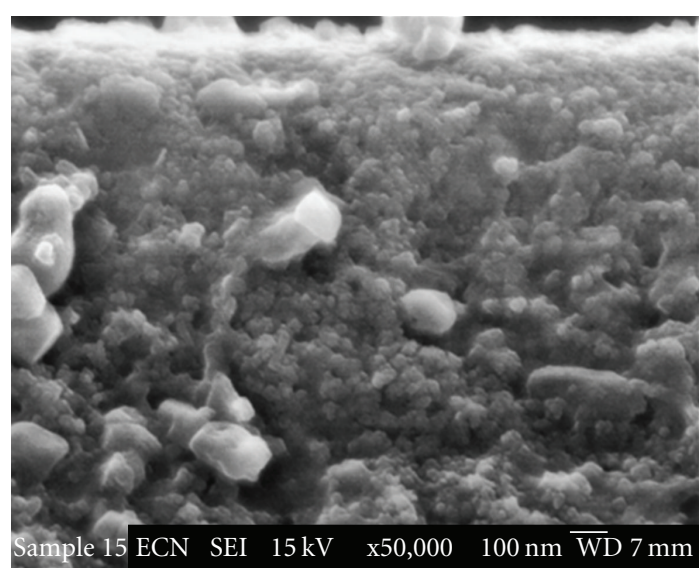

(d)

FIGURE 2: SEM cross-sections of ssDSCs with overlayers of (a) $580 \mathrm{~nm}$; (b) $190 \mathrm{~nm}$ (C) 10 nm and (d) $0 \mathrm{~nm}$.

$25 \mathrm{mg} \mathrm{mL}^{-1}$ spiro-MeOTAD) are short circuited due to the direct connection between the $\mathrm{TiO}_{2}$ electrode and the counter electrode. It is interesting to note, however, that the sample with an overlayer of only $\sim 10 \mathrm{~nm}$ (as shown in Figure 2(c)) performs with roughly the same efficiency as those cells with much thicker overlayers. (See supplementary material available at doi: 10.1155/2011/513089).

3.3. Desorption to Measure Mass. After dissolving the ssDSC in chlorobenzene for 1 hour, the concentration of spiroMeOTAD was determined using Beer's law, as pioneered by Ding et al. [19]. The change in UV-vis absorption, at $390 \mathrm{~nm}$, of the desorbed sample was measured spectroscopically and compared to the optical densities, at the same wavelength, of solutions with known spiro-MeOTAD concentrations. Lambert-Beer's law was experimentally verified to be valid in the range of $25-300 \mathrm{mg} \mathrm{mL}^{-1}$.

3.4. Calculated Mass. As an alternative to using the desorption measurements to determine the spiro-MeOTAD mass, the mass was calculated using (2), which involves using three measured parameters: the thicknesses of the $\mathrm{TiO}_{2}$ and the overlayer, $t_{\mathrm{TiO}_{2}}$ and $t_{\mathrm{OL}}$, (to express volumes with assumed areas of $1 \mathrm{~mm}^{2}$ ), and the density, $\rho$; one parameter retrieved from the literature, the porosity, $p$; the parameter of interest, the filling fraction, $F$.

$$
\begin{aligned}
& \text { spiro }_{\text {calc mass }} \\
& \quad=\left(\left(t_{\mathrm{TiO}_{2}} 1 * \mathrm{~mm}^{2}\right) * p * F+\left(t_{\mathrm{OL}} * 1 \mathrm{~mm}^{2}\right)\right) * \rho .
\end{aligned}
$$

The calculated mass in the pores is the quantity expressed in (2) minus the second term, that is, the contribution of the overlayer. The density of spiro-MeOTAD was determined to be $1 \pm 0.1 \mathrm{~g} / \mathrm{cm}^{3}$, as detailed in the experiment section.

The observed desorbed mass agrees with the calculated total mass of spiro-MeOTAD (2) at low concentrations, but is significantly lower at higher concentrations (Figure 5). One explanation is that the films infiltrated with higher spiro-MeOTAD concentrations may require a longer desorption time than 1 hour to completely desorb all the spiro-MeOTAD. The desorbed $\mathrm{TiO}_{2}$ films were examined spectroscopically, but were too scattering to give meaningful data. On the other hand, Ding et al. [19] also used desorption times of one hour and confirmed the total desorption of the spiro MeOTAD by XPS. Another possibility that is explored below, is that the calculated mass does not take into account 


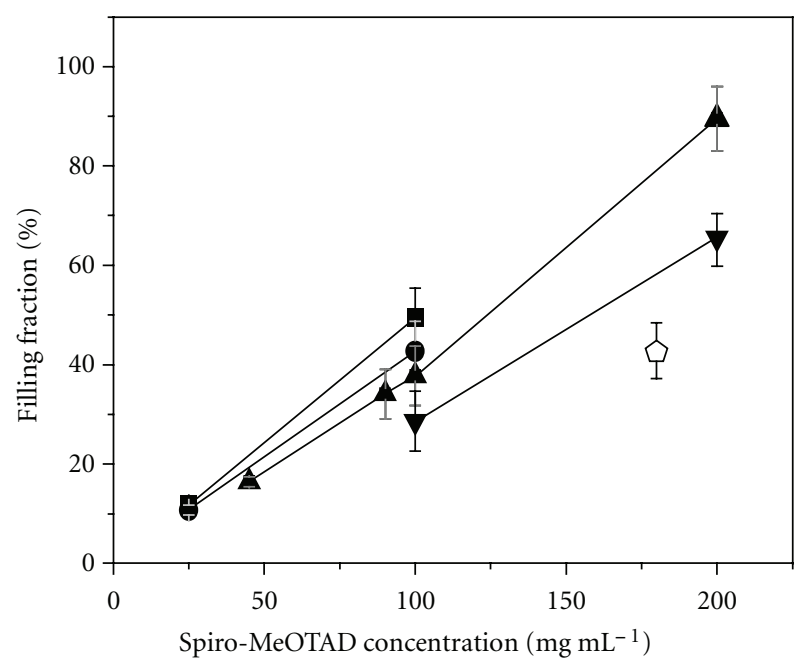

FIGURE 3: Filling fraction versus spiro-MeOTAD concentration, calculated according (1a) and (1b), for samples with $\mathrm{TiO}_{2}$ thicknesses of: $1.4 \mu \mathrm{m}(\boldsymbol{\square}) ; 1.7 \mu \mathrm{m}(\bullet) ; 2 \mu \mathrm{m}(\mathbf{\Delta}) ; 3 \mu \mathrm{m}(\mathbf{\nabla}) ; 5 \mu \mathrm{m}(\bullet)$.

the effect of increased viscosity at higher spiro-MeOTAD solution concentrations, which lowers the capillary force to draw the liquid into the oxide matrix (see (6) below).

3.5. Characteristic Penetration Length. By multiplying the filling fraction by the thickness of the $\mathrm{TiO}_{2}$ film, a characteristic penetration length (CPL) may be determined:

$$
\mathrm{CPL}=F * t_{\mathrm{TiO}_{2}} .
$$

The term "characteristic penetration length" may suggest that the solution penetrates the film from top to bottom, infiltrating all the porous spaces equally, but this is not realistic considering the experimental evidence that there is typically no concentration gradient across the ssDSC $[15,17,18]$. The $\mathrm{TiO}_{2}$ particulate film is composed of pores of various diameters which randomly branch and neck, and the primary infiltration mechanism is thought to be capillary action [19], which depends on the pore diameter. Nevertheless, it is a way of comparing the relative filling of one film with another. The CPL is found to be a constant, for all ssDSCs of a given spiro-MeOTAD concentration, independent of film thickness. (Please see supporting information for electrical characteristics.)

The mass, $m$, is related to the CPL through (4), using the volume (area, $A$, times length, $\mathrm{CPL}$ ), porosity, $p$, and density, $\rho$.

$$
\begin{aligned}
m & =A * \mathrm{CPL} * \rho * p \\
& =1 \mathrm{~mm}^{2} *\left(t_{\mathrm{TiO}_{2}} * F\right) * \rho * p .
\end{aligned}
$$

Equation (4) is the same as (2) minus the overlayer. In Figure 5, the experimentally desorbed mass (which includes the overlayer) for ssDSCs of different spiro-MeOTAD concentrations are compared to the calculated total mass, as well as the calculated mass in the pores (or equivalently, the
CPL times porosity). The filling fraction used in the calculated quantities overestimates the mass of spiro-MeOTAD infiltrated in the pores. (Equivalently, we could have used the desorbed mass (see supplementary materials) and (2) to compare empirical filling fractions to filling fractions calculated with (1a) and (1b), with the latter similarly overestimating the experimental.) While the filling fraction allows for variations in wet overlayer thicknesses, $t_{\mathrm{WET}}$, it does not account for the effect of viscosity on the capillary infiltration force. Therefore a correction based on viscosity is proposed to bring the CPL, and the filling fraction, $F$, more in line with the observed desorbed mass.

The relationship between $t_{\mathrm{WET}}$ and the spiro-MeOTAD concentration is an exponential one, as shown in Figure 4(a), suggesting that the higher concentrations have a higher viscosity, requiring more centrifugal force to be spun off than lower concentrations of spiro-MeOTAD. The film thickness, as determined by spin-coating at a fixed speed, is a balance between the drying rate and the radial shear force on the solution. The viscosity of the solution is the resistance of the solution to deformation by the shear force. For many materials, up to concentrations of $50 \%$, the viscosity of solution increases for higher concentrations of solute [16]. The results show that spiro-MeOTAD in chlorobenzene also follows this trend.

An empirical correction factor may be proposed to account for the exponentially thicker layer at higher concentrations. Extrapolating the exponential function to a concentration of $0 \mathrm{mg} \mathrm{mL}^{-1}$ gives a $t_{\mathrm{WET}}$ of 3.5 microns, the value at which the CPL-based calculation agrees well with the calculated mass. The data shows that an increase in the viscosity with concentration has an inverse impact on the penetration length. Therefore the CPL may be adjusted with the ratio of $t_{\mathrm{WET} 0} / t_{\mathrm{WET}}$ to account for this effect. Indeed, an improved characteristic length which is more in line with the experimental results is obtained, as indicated in (5), and plotted in Figure 5

$$
\mathrm{CPL}_{\text {corr }}=\mathrm{CPL} * \frac{t_{\mathrm{WET} 0}}{t_{\mathrm{WET}}}, \quad F_{\text {corrected }}=F * \frac{t_{\mathrm{WET} 0}}{t_{\mathrm{WET}}} .
$$

This may be useful to estimate the extent of filling of spiro-MeOTAD in the pores of a $\mathrm{TiO}_{2}$ nanoparticulate film. The penetration of a solution into a wetted capillary, or porous medium, is described by the Lucas-Washburn [2022] equation, in which $\ell$ is the penetration length, $r_{\text {eff }}$ is the effective hydrodynamic pore radius, $\gamma$ is the surface tension, $\eta$ is the viscosity, $\theta$ is the contact angle, and $t$ is the time, as given in (4)

$$
l^{2}=\left(\frac{\gamma}{\eta} \frac{\cos \theta}{2}\right) r_{\mathrm{eff}} t
$$

Equation (6) shows that the penetration length is a function of the viscosity of the penetrating solution. The application of this equation requires a determination of the effective radius in the tortuous particulate $\mathrm{TiO}_{2}$ film, which, for example, has been performed for alumina packed beds [21]. It clearly shows the relationship of viscosity to penetration length and may be the focus of future work in understanding 


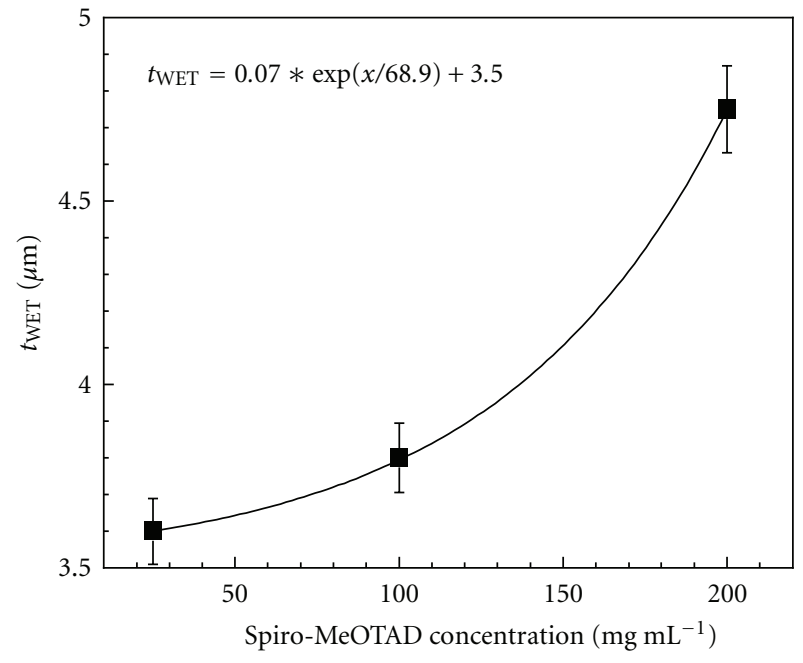

(a)

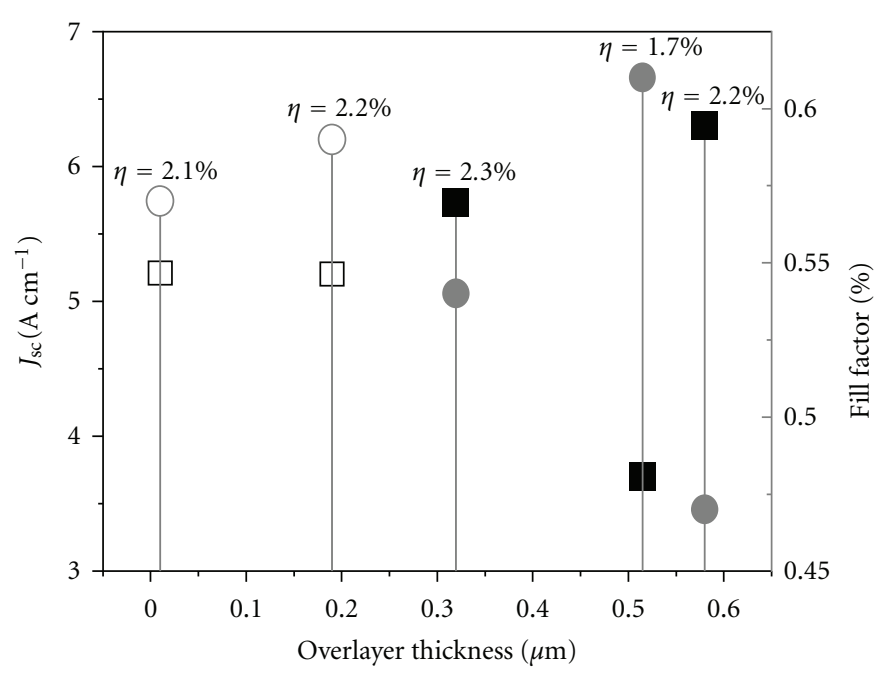

(b)

FIgURe 4: (a) Wet layer thickness $\left(t_{\mathrm{WET}}\right)$ as a function of the spiro-MeOTAD concentration, fitted with an exponential. (b) Short circuit currents (squares) and fill factors (circles) for ssDSCs as a function of spiro-MeOTAD overlayer thicknesses, for spiro-MeOTAD concentrations of $100 \mathrm{mg} \mathrm{mL}^{-1}$ (open symbols) and of $200 \mathrm{mg} \mathrm{mL}^{-1}$ (closed symbols).

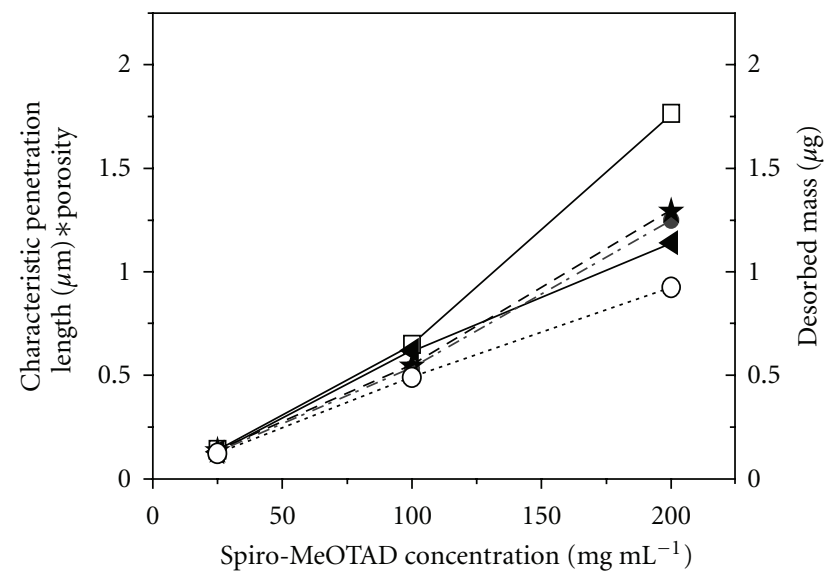

Figure 5: The scale of the CPL $(\mu \mathrm{m})$, times the porosity (\%), is the same as the one for the desorbed mass $(\mu \mathrm{g})$ for spiro-OMeTAD with a density of $1 \mathrm{~g} / \mathrm{cm}^{3}$ (see text). Average calculated and experimental values of the mass are plotted versus spiro-MeOTAD concentration. The experimentally determined mass desorbed from the samples $(\varangle)$ is much lower than the calculated total mass $(\square)$ and should be greater than the calculated mass in the pores $(\star)$ because the former also includes the overlayer. The uncorrected CPL $(\bullet)$ is equal to the calculated mass in the pores $(\star)$. These values indicate that the filling fraction overestimates the amount of spiroMeOTAD which actually infiltrates the pores. The correction for viscosity effects $(\bigcirc)$ for higher concentrations of spiro-MeOTAD gives an improved value for the CPL, or calculated mass in the pores. (The standard deviation of all CPL and desorbed mass values is $<0.12 \mu \mathrm{m}$.)

and optimizing the infiltration of a hole conductor into a $\mathrm{TiO}_{2}$ film. Understanding the pore filling mechanism reflected by the filling fraction is a key to optimizing the pore filling. References to the CPL in this paper from this point on will refer to the $\mathrm{CPL}_{\mathrm{corr}}$, which is corrected for the effects of viscosity.

3.6. Photoinduced Absorption Spectroscopy: Relation to Filling Fraction. The photoinduced absorption spectroscopy technique allows optical detection of excited species generated by photoexcitation, such as the oxidized states of the dye, Z907, and the hole conductor, spiro-MeOTAD, in a ssDSC. After injection of the electron by the dye into the conduction band of the $\mathrm{TiO}_{2}$, the dye cation is normally regenerated to its neutral state by an electron from the spiro-MeOTAD after a period ranging from less than ps to greater than ns [6]. In the absence of a hole conductor, an electron from the $\mathrm{TiO}_{2}$ recombines with the oxidized dye cation after a period of hundreds of microseconds [2], during which the absorption spectrum of the oxidized dye may be observed.

When spiro-MeOTAD perfectly infiltrates the sensitized $\mathrm{TiO}_{2}$ film and regenerates the dye, the photoinduced absorption features of the oxidized dye are replaced with that of oxidized spiro-MeOTAD $[6,7,15,17,18]$. In the extended visible spectral range (400-1000 nm), many signals may overlap due to contributions of the oxidized dye (absorption and bleaching bands) [23], electrons in $\mathrm{TiO}_{2}$ $[24,25]$, and oxidized spiro-MeOTAD [18]. This confluence of signals in the visible region makes it very difficult to analyze spectra. Even when the separate spectral features of the oxidized dye and spiro-MeOTAD are known, near steady state photoinduced absorption spectra in the spectral range of 400-1000 $\mathrm{nm}$ cannot always be fitted with a linear addition of the independent oxidized dye or hole-conductor, because the electron density of the $\mathrm{TiO}_{2}$ surface may lead to spectral shifts in the ground state absorption of dyes and thereby to additional spectral variations near the bleaching band [17]. Alternatively, the observation window may be extended to the near infrared region of the spectrum, where 
oxidized spiro-MeOTAD shows a broad absorption band and the oxidized ruthenium dyes do not absorb. This strategy was used by Snaith et al. in a qualitative analysis of their photoinduced absorption spectra [18].

The PIA spectrum of only the dye $\mathrm{Z} 907$ on $\mathrm{TiO}_{2}$ reveals a positive $\Delta T T^{-1}$ signal (i.e., bleaching) with a maximum at $515 \mathrm{~nm}$, and a negative signal (i.e., absorption) peaking between $750-800 \mathrm{~nm}$. (Figure 6(a)). The spectral shape is very similar to that reported for $\mathrm{TiO}_{2}$ films sensitized with the well-studied and structurally similar dyes N3 (cis-Ru(dcbpy) $\left.)_{2}(\mathrm{NCS})_{2}\right)$ [12-14, 26] and N719 (its bisdeprotonated analog) [27]. Therefore, we can safely attribute the positive signal to the bleaching band of Z907 and the negative signal to the absorption band of oxidized $\mathrm{Z} 907$. Additionally, a weak absorption tail of electrons in $\mathrm{TiO}_{2}{ }^{-}$is present in the visible to near infrared region $[24,25]$.

Although steady-state spectra of chemically oxidized spiro-MeOTAD in solution $[28,29]$ as well as spectroelectrical studies [29] of spiro-MeOTAD in $\mathrm{TiO}_{2}$ films are available, spectral near steady-state PIA features of optically oxidized spiro-MeOTAD in the solid state may provide slightly different absorption features. Therefore [70]PCBM was used as a photosensitizer to generate a photoinduced absorption spectrum (Figure 6(a)) of oxidized spiro-MeOTAD in a solid composite blend with [70] $\mathrm{PCBM}$ on $\mathrm{TiO}_{2}$ and in the absence of dye Z907. [70]PCBM is used because it can be photoexcited and accept electrons from spiro-MeOTAD [2931 , as a result of its strong ground state absorption in the visible region and strong electron accepting properties [32]. The PIA spectrum of the [70]PCBM:spiro-MeOTAD mixture in $\mathrm{TiO}_{2}$ reveals two absorption bands in the visible region at ca. $515 \mathrm{~nm}(2.41 \mathrm{eV})$ and $700 \mathrm{~nm}(1.68 \mathrm{eV})$, and one in the near infrared at $1500 \mathrm{~nm}(0.83 \mathrm{eV})$ as shown in Figure 6(a). These three bands are attributed to oxidized spiro-MeOTAD, because of good agreement with previously reported spectra that were obtained by stepwise chemical oxidation $[28,29]$ or in spectroelectrical studies $[29,33]$. In dichloromethane solution, Struijk found two absorption bands in the visible, a strong band at $521 \mathrm{~nm}$ and a less intense band at $678 \mathrm{~nm}$, and one in the near infrared, at $1514 \mathrm{~nm}$, after stepwise chemical oxidation [28] A 5-25 nm shift is typically observed when comparing the spectra of a photoactive species in solution to one in the solid state and is due to molecular interaction with the local environment.

Having established the separate contributions of oxidized Z907 and spiro-MeOTAD, it is possible to analyze PIA spectra of $\mathrm{TiO}_{2}$ films containing both $\mathrm{Z} 907$ and spiro-MeOTAD. For ssDSCs, the PIA spectrum strongly changes with increasing spiro-MeOTAD concentration from 25 to $180 \mathrm{mg} \mathrm{mL}^{-1}$ (Figure 6(b)). For the lowest concentration, the absorption maximum at $780 \mathrm{~nm}$ and the presence of a bleaching band below $600 \mathrm{~nm}$ (Figure 6(b)) are signatures of oxidized Z907. Contributions of oxidized spiro-MeOTAD are visible from the band at $1450 \mathrm{~nm}$, and from its absorption between 550 and $800 \mathrm{~nm}$. This latter absorption peak overlaps with the bleaching band of the dye and thereby causes an altered form of the positive $\Delta T T^{-1}$ band below $600 \mathrm{~nm}$, as compared to the dyed film without spiro-MeOTAD (Figure 6(a)). For the highest concentration of spiro-MeOTAD the absorption maxima of the bands are 515, 730, and $1450 \mathrm{~nm}$, in good correspondence to the spectrum obtained for the film using [70]PCBM as photosensitizer. This indicates that at the highest concentration, the major part of the dye is regenerated by spiro-MeOTAD. However, comparison of the spectrum of the ssDSC, with $180 \mathrm{mg} \mathrm{mL}^{-1}$ spiro-MeOTAD, with that of the spiro-MeOTAD/PCBM blend (Figure 6(c)) shows that even for the highest concentration of spiroMeOTAD (triangles), there is still some oxidized dye present (visible by the bleaching band at $565 \mathrm{~nm}$ and the additional absorption around $750 \mathrm{~nm}$ ). Furthermore, the additional absorption in the region 850-1200 $\mathrm{nm}$ may be explained with the absorption of free electrons in $\mathrm{TiO}_{2}$ [24].

Overall, with increasing spiro-MeOTAD concentration, two major spectral changes occur: (1) between 750 and $850 \mathrm{~nm}$ the $\Delta T T^{-1}$ signal intensity reduces (relative to the $1450 \mathrm{~nm}$ peak) and (2) between 525 and $600 \mathrm{~nm}$ the positive (i.e., bleaching) signal turns into a negative (i.e., absorption) signal (Figure 6(b)). With increasing spiro-MeOTAD content, both absorption changes are due to lower contribution of the strong absorption (around $800 \mathrm{~nm}$ ) and bleaching (around $565 \mathrm{~nm}$ ) of oxidized Z907, relative to oxidized spiroMeOTAD. By plotting the absorbance at $565 \mathrm{~nm}$ versus that at $825 \mathrm{~nm}$, as in Figure 7(a), a linear relation is found with increasing spiro-MeOTAD concentration, when the spectra is normalized at the spiro-MeOTAD $1450 \mathrm{~nm}$ peak. This indicates that the spectral changes are due to the same photoexcited species, which we conclude is the oxidized dye.

Plotting all the data gives a slope of -2.0 , but the PIA signal $\left(\Delta T T^{-1}\right)$ of those samples with the lowest concentration of spiro-MeOTAD are much more scattering than the rest of the samples. They are a bilayer, in which the effective refractive index of one layers is the average of spiro-MeOTAD, $\mathrm{TiO}_{2}$ and air and the other layer is only an average of $\mathrm{TiO}_{2}$ and air, and is consistent with other observations of concentration gradients in samples with low concentrations of spiro-MeOTAD [17]. These samples clearly scatter the light differently than a single composite layer of spiro- MeOTAD, $\mathrm{TiO}_{2}$ and air. Highly scattering samples may dramatically influence the accuracy of the PIA measurement by lowering the magnitude of both $\Delta T$ and $T^{-1}$, introducing a large error in their ratio. When these points are disregarded, the linear fit has a slope of -2.2 . A line with a slope of -2.4 is also plotted to show that this slope is also within the accuracy of the measurement and/or the fit. A slope of -2.4 is expected because the ratio of PIA signal intensities at $565 \mathrm{~nm}$ to $825 \mathrm{~nm}$ for the dye on $\mathrm{TiO}_{2}$ alone, without spiro-MeOTAD, is -2.4 . (Figure 6(a)). The ratio of the dye cation absorption peak at $825 \mathrm{~nm}$, or at $565 \mathrm{~nm}$, to the spiro-MeOTAD cation peak at 1450 may be used to extract the relative dye cation concentration from the absorption spectrum of the ssDSC.

The PIA signal intensities for the $565 \mathrm{~nm}$ and $825 \mathrm{~nm}$ peaks, relative to the $1450 \mathrm{~nm}$ spiro-MeOTAD peak, are plotted as a function of filling fraction in the inset of Figure 7(b). Because the filling fraction is a nondimensional measure of concentration, it has an exponential relationship to the transmitted light intensity, as predicted by the Beer-Lambert law, given in (7), where $I$ is intensity, $\varepsilon_{i}$ is 


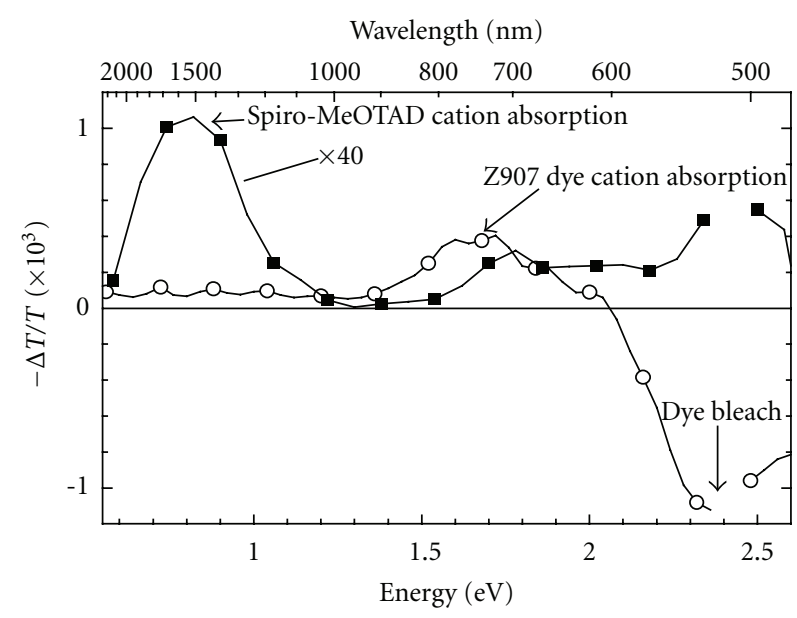

(a)

Wavelength (nm)

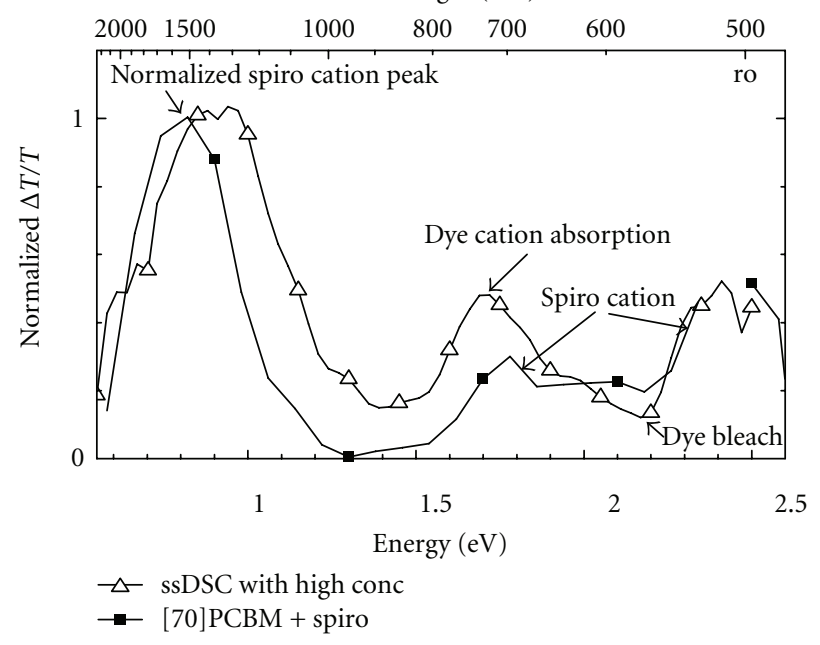

(c)

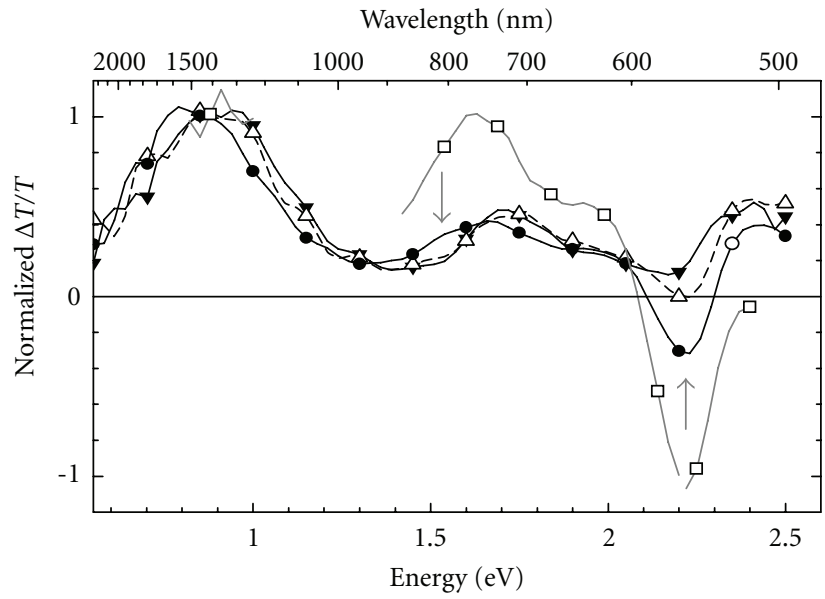

(b)

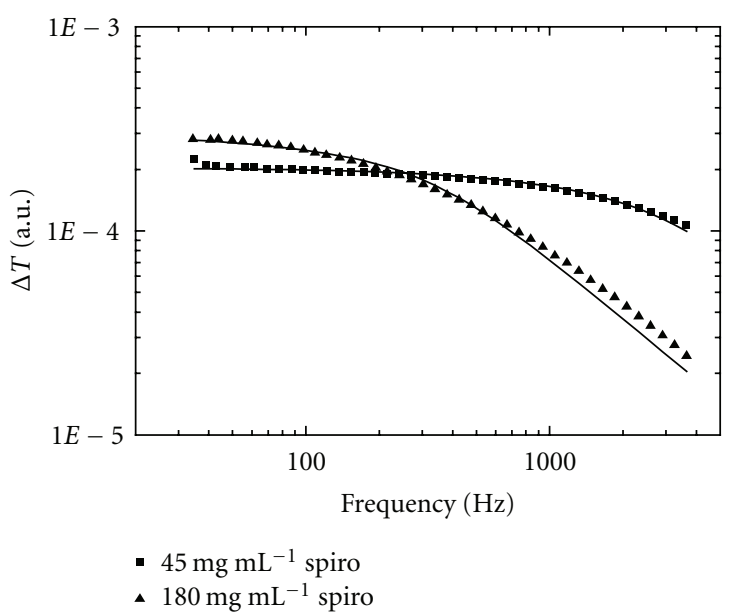

(d)

Figure 6: Photoinduced absorption spectra of (a) dye $\mathrm{Z907}$ in $\mathrm{TiO}_{2}(\bigcirc)$, and [70]PCBM blended with spiro-MeOTAD on TiO 2 multiplied with a factor of 40); (b) $\mathrm{TiO}_{2}$ sensitized with dye Z907, with spiro-MeOTAD, normalized at the peak at 1400-1500 nm (0.83$0.89 \mathrm{eV})$, using spiro-MeOTAD concentrations of $25(\square), 45(\bullet), 90(\triangle)$, and $180(\boldsymbol{\nabla}) \mathrm{mg} \mathrm{mL}^{-1}$; (c) spectrum of a ssDSC: sensitized (Z907) $\mathrm{TiO}_{2}$ infiltrated with a high concentration of spiro-MeOTAD $\left(200 \mathrm{mg} \mathrm{mL}^{-1}\right),(\triangle)$; compared with the spectrum of the spiroMeOTAD/PCBM blend, ( $\mathbf{\square})$. Spectra were recorded using excitation wavelengths of $514 \mathrm{~nm}(\mathrm{a}, \mathrm{c})$ and $458 \mathrm{~nm}$ (b, c). (d) Frequencydependent PIA intensities for $\mathrm{TiO}_{2}$ samples sensitized with dye Z907, infiltrated with $45(\mathbf{\square})$ or $180(\mathbf{\Delta}) \mathrm{mg} \mathrm{mL}^{-1}$ spiro-MeOTAD solution. The measurements were recorded at $1.05 \mathrm{eV}(1180 \mathrm{~nm})$. The solid lines are fits to the data $(13)$ and result in steady-state lifetimes of 115 and $995 \mu$ s for the low and the high spiro-MeOTAD concentration, respectively.

the extinction coefficient of species $i, c_{i}$ is the concentration of species $i$ and $l$ is path lengt.

$$
\begin{aligned}
\log \left(\frac{I_{0}}{I}\right) & =\sum \varepsilon_{i} c_{i} l \\
& =\varepsilon_{\text {dye cation }} c_{\text {dye cation }} l+\varepsilon_{\text {spiro MeOTAD }} c_{\text {spiro MeOTAD }} l
\end{aligned}
$$

Normalizing the data at the spiro-MeOTAD peak at 1450 has two effects: (i) the observed signal at the $825 \mathrm{~nm}$ peak is now a ratio of the signals at the 825 and $1450 \mathrm{~nm}$ peaks and (ii) the expression $\left(\boldsymbol{\varepsilon}_{\text {spiro+ }}^{1450} * \mathbf{c}_{\text {spiro+ }}^{1450} * \mathbf{l}\right)$ is set to a magnitude of one. The Beer-Lambert law for the normalized data may be written as shown in (8) and simplified with the introduction of constants for the ratio of the extinction coefficients for the respective peaks, as shown in (9)

$$
\begin{aligned}
& \frac{\log (\Delta I)_{825}}{\log (\Delta I)_{1450}} \\
& =\frac{\left(\varepsilon_{\text {spiro }^{+}}^{825} c_{\text {spiro }} l+\varepsilon_{\text {dye }^{+}}^{825} c_{\text {dye }^{+}} l\right)}{\varepsilon_{\text {spiro }^{+}}^{1450} c_{\text {spiro }} l} \\
& =\frac{\varepsilon_{\text {spiro }}{ }^{+}}{\varepsilon_{\text {spiro }+}^{1450}}+\frac{\varepsilon_{\text {dye }^{+}}^{825} c_{\text {dye }^{+}} l}{\varepsilon_{\text {spiro }^{+}}^{1450} c_{\text {spiro }^{+}}}
\end{aligned}
$$




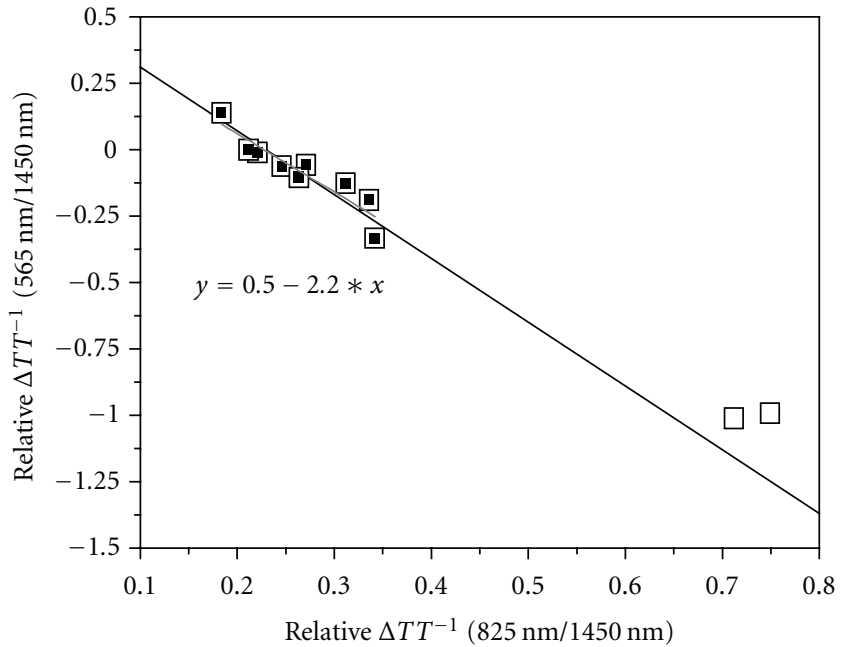

(a)

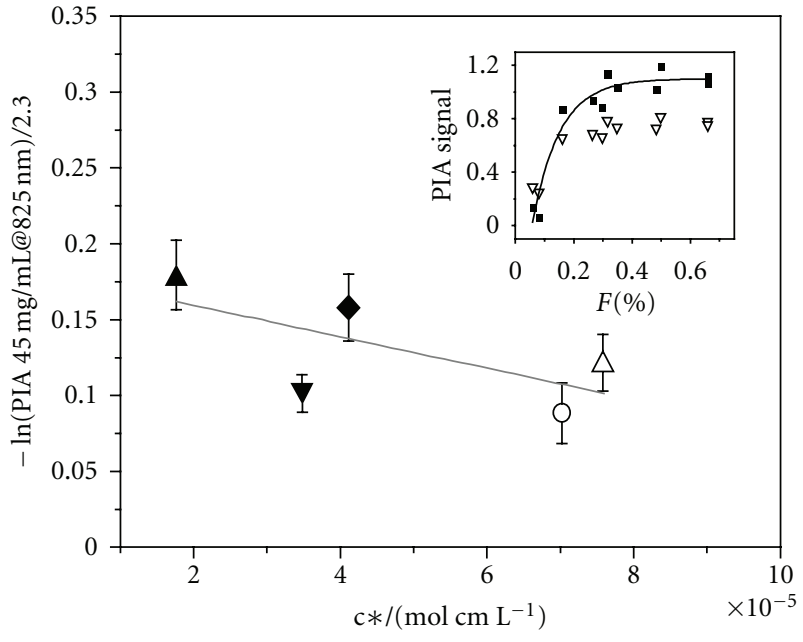

(b)

Figure 7: (a) $\Delta T T^{-1}$ signal intensities relative to the peak at $1450 \mathrm{~nm}$, for $565 \mathrm{~nm}\left(\left(\Delta T_{565 \mathrm{~nm}} T_{565 \mathrm{~nm}}{ }^{-1}\right) /\left(\Delta T_{1450 \mathrm{~nm}} T_{1450 \mathrm{~nm}}{ }^{-1}\right), y_{\text {-axis })}\right.$ compared to $825 \mathrm{~nm}\left(\left(\Delta T_{825 \mathrm{~nm}} T_{825 \mathrm{~nm}}{ }^{-1}\right) /\left(\Delta T_{1450 \mathrm{~nm}} T_{1450 \mathrm{~nm}}{ }^{-1}\right), x\right.$-axis). The solid line is a linear fit to the data, excluding the highly scattering points at the lowest concentration: $y=-2.2 x+0.5$. The dashed line shows $y=-2.4 x+0.55$. (b) The $\ln ($ relative PIA signal at $825 \mathrm{~nm}) / 2.3$ is plotted against the concentration times length $\left(\mathrm{mol} \mathrm{cm} \mathrm{L}^{-1}\right)$. The spiro-MeOTAD concentrations are $45(\boldsymbol{\Delta}), 90$ $(\boldsymbol{\nabla}), 100(\checkmark) \mathrm{mg} \mathrm{mL}^{-1} ; 180(\bigcirc) \mathrm{mg} \mathrm{mL}^{-1} ; 200(\Delta) \mathrm{mg} \mathrm{mL}^{-1}$. Inset: $\Delta T T^{-1}$ signal intensity relative to the peak at $1450 \mathrm{~nm}$, for $825 \mathrm{~nm}$ $\left(\left(\Delta T_{825 \mathrm{~nm}} T_{825 \mathrm{~nm}}{ }^{-1}\right) /\left(\Delta T_{1450 \mathrm{~nm}} T_{1450 \mathrm{~nm}}{ }^{-1}\right), \boldsymbol{\square}\right)$ and for $565 \mathrm{~nm}\left(\left(\Delta T_{565 \mathrm{~nm}} T_{565 \mathrm{~nm}}{ }^{-1}\right) /\left(\Delta T_{1450 \mathrm{~nm}} T_{1450 \mathrm{~nm}}{ }^{-1}\right)\right.$, ( $\left.\nabla\right)$ compared to the filling fraction obtained in Section 2.1. The data are fitted with exponential functions: $y=-2 * \exp (-x / 0.1)+1.1($ solid line) and $-1 * \exp (-x / 0.1)+0.75$.

$$
=B+A *\left(\frac{c_{\text {dye }^{+}}}{c_{\text {spiro }^{+}}}\right), \quad \text { where } A=\left(\frac{\varepsilon_{\text {dye }^{+}}^{825}}{\varepsilon_{\text {spiro }^{+}}^{1450}}\right), B=\left(\frac{\varepsilon_{\text {spiro }}^{825}}{\varepsilon_{\text {spiro }}^{1450}}\right) \text {. }
$$

If the extinction coefficients and the concentrations of the dye and spiro MeOTAD cations are known, then (9) is quite useful. But, it is also possible to reformulate (8) so that the normalized PIA signal provides a measure of the dye cation population, relative to the concentration of spiro-MeOTAD present, without knowledge of the respective extinction coefficients or cation concentrations. It is quite evident that the dye cation population, that is, those dyes that are not regenerated by the hole conductor, is related to the concentration of the hole conductor, and so we can let the ratio of the dye cation density to the spiro-cation density be a function of the spiro-MeOTAD concentration, as expressed in (10). Now, a relationship between the normalized PIA signal and the concentration of spiro-MeOTAD can be written using an effective extinction coefficient as shown in (11)

$$
\begin{aligned}
& \text { let } \frac{c_{\text {dye }^{+}}}{c_{\text {spiro }^{+}}}=f\left(c_{\text {spiro }}\right)=\xi * c_{\text {spiro }}, \\
& \text { let } \varepsilon_{\text {effective }}^{\prime}=\frac{\varepsilon_{\text {dye }^{+}}^{825}}{\varepsilon_{\text {spiro }}^{1450}} * \frac{\xi}{l}, \\
& \frac{\log (\Delta I)_{825}}{\log (\Delta I)_{1450}}=B+\varepsilon_{\text {effective }}^{\prime} * c_{\text {spiro }} * l .
\end{aligned}
$$

It is interesting to apply (11) to the PIA data, using the CPL (i.e., $F * t_{\mathrm{TiO}_{2}}$ ) in (12), to calculate the effective extinction coefficient, with units of $\mathrm{M}^{-1} \mathrm{~cm}^{-1}$, of the relative intensity signal at $825 \mathrm{~nm}$, as plotted in Figure 7(b).

$$
\begin{aligned}
\mathrm{cl}\left[\frac{\mathrm{molcm}}{L}\right] & =\frac{\rho}{M_{\text {spiroMeOTAD }}} * p * F * t_{\mathrm{TiO}_{2}} \\
& =\frac{1000 \mathrm{~g} / \mathrm{L}}{1230 \mathrm{~g} / \mathrm{moL}} * 0.68 * \mathrm{CPL}[\mu \mathrm{m}] * \frac{\mathrm{cm}}{10^{4} \mu \mathrm{m}} .
\end{aligned}
$$

Figure 7(b) shows that the data may be linearly fitted for all concentrations higher than $25 \mathrm{mg} \mathrm{mL}^{-1}$. The error bars are based upon the deviation of a group of three measurements, and the line has an intercept of $0.16 \pm 0.02$ and the slope, $-814 \pm 120$. The slope of this line is the effective extinction coefficient for this system. Here, as in the linear fit of the optical data plotted in Figure 7(a), the data points for the very low concentrations of spiro-MeOTAD were not included in the linear fit. Furthermore, in the event of a bi-layer $\left(\mathrm{TiO}_{2}+\right.$ spiro-MeOTAD + air $\mid \mathrm{TiO}_{2}+$ air $)$, the relationship between the spiro-MeOTAD concentrations and the dye and oxidized spirocations, assumed in (10), would break down. Indeed, as the concentration of spiro-MeOTAD approaches zero, so will the concentration of spiro-MeOTAD cation, and the expression for $\xi$ will become undefined and very near to this singularity, the relationship becomes superlinear. Despite these considerations, employing this relationship is useful for interpreting the data in the range of concentrations from $45 \mathrm{mg} \mathrm{mL}^{-1}$ up through at least $300 \mathrm{mg} \mathrm{mL}^{-1}$. 
It is possible to estimate the magnitude of $c * l$ that is necessary to eliminate the dye cation signal. By extrapolating the linear fit in Figure 7(b) to the case where there is no signal from the dye cation, that is, to $y=0$, the abscissa, $c * l$, is equal to $1.71 \times 10^{-4} \pm 2.6 \times 10^{-5} \mathrm{Mcm}$, which can be converted to a CPL of $3.1 \pm 0.46 \mu \mathrm{m}$ using (12). The average (corrected) CPL of the samples with spiroMeOTAD concentrations of $200 \mathrm{mg} \mathrm{mL}^{-1}$ is 1.4. Comparison of these two values shows that a doubling of the characteristic penetration length of spiro MeOTAD is required, than currently achieved, in order to be able to regenerate, and thus functionalize, all the dye molecules in a conventionally sensitized ssDSC.

A sample may have a filling fraction of $90 \%$ but if the $10 \%$ of the remaining pore space (i.e., narrow pores) contain a third of the dye molecules then the filling is not optimum. Usually high filling fractions can be only achieved with films not greater than 2-2.5 microns. Thicker films would lead to higher light absorption, higher currents, and higher efficiencies. Indeed, the liquid electrolyte DSC's are routinely made to be 8-10 microns thick. Equation (6) shows that the penetration depth of the capillary force depends on viscosity, wetting and the pore radius. (We can assume, as did Snaith et al. [18] that the chlorobenzene completely wets the $\mathrm{TiO}_{2}$.) In this case, optimization of the pore filling should address the viscosity of the concentrated spiro-MeOTAD and/or the effective pore radius of the $\mathrm{TiO}_{2}$ film, to optimize the amount of spiro-MeOTAD which can infiltrate into the pores by capillary action.

The PIA measurements in this work were made at a frequency of $275 \mathrm{~Hz}$, very near the crossover point of the two curves in Figure 6(d), at which there is little variation of signal intensity with spiro MeOTAD concentration, and appropriate for a measurement relative to a constant spiro MeOTAD contribution and the analysis used above. However, to quantitatively determine the number of [non] regenerated cations, or the HTY, the extinction coefficients of the two species must be independently known, and the effect of lifetime upon the measurement must be taken into account. The magnitude of the PIA signal is proportional to $g$, the efficiency of generation of the photoinduced species; $I$, the pump intensity; $\tau_{s}$ the lifetime of a photoexcitation under steady-state conditions, and $\alpha=$ $(2 v \tau s)^{-1}$.

$$
-\Delta T \propto \frac{g I \tau_{s} \alpha \tanh \alpha}{(\alpha+\tanh \alpha)} .
$$

This equation can be used to detect $\tau_{s}$ from chopper frequency-dependent PIA measurements. This results in steady-state lifetimes of $\tau_{s}=115 \mu$ s for a low spiro-MeOTAD concentration of $45 \mathrm{mg} \mathrm{mL}^{-1}$ and to $\tau_{s}=995 \mu \mathrm{s}$ for a four times higher spiro-MeOTAD concentration. Such nonequal lifetimes with different hole conductor concentrations complicate quantitative determination of hole transfer yields using near steady-state photoinduced absorption spectra, because the lifetimes are shorter than the period of the chopper $\left(\nu^{-1}=3.6 \mathrm{~ms}\right)$. In this case, an increase in lifetime leads to an increase in PIA intensity. For lifetime-independent and hence more quantitative detection using near-state PIA measurements, much higher frequencies would be required. For example, when measuring at $10 \mathrm{kHz}$, an increase in lifetime from 0.1 to $1 \mathrm{~ms}$ would lead to an increase in PIA intensity as a result of the increased lifetime of only $4 \%$.

This analysis shows that a single PIA measurement at two different wavelengths ( $825 \mathrm{~nm}$ and $1450 \mathrm{~nm}$ ) can be used as a measure for the hole transfer yield (HTY). Furthermore, this method is more robust than the previous method described by Kroeze et al. [15] In that the quantification may be obtained from a single measurement set, therefore it is not necessary to measure the ssDSC before and after filling with the hole conductor which requires that the light intensities and sample repositioning must be as identical as possible.

\section{Conclusions}

We prepared ssDSCs with a range of $\mathrm{TiO}_{2}$ thicknesses and filling fractions. The calculated mass based on the filling fraction, as proposed by Snaith, was greater than the experimentally desorbed mass. Because the effects of viscosity were observed in the thicknesses of the spiro MeOTAD films spun on flat substrates, a correction factor was proposed for the filling fraction to account for the effects of viscosity in capillary infiltration. According to the BeerLambert law, it was shown that PIA signal is related to the filling fraction, and the CPL, through an effective extinction coefficient, which was determined for this material system, allowing the relative dye cation density to be deduced. The optimum value of the CPL, for the sample range of 1.4 to $5 \mu \mathrm{m}$ investigated here, was determined to be $3.1 \pm 0.46$ microns which is roughly double the average CPL for the samples used in this study (see supplementary material). This suggests that a solution with a higher concentration of hole conductor and a lower viscosity and/or a greater effective pore radius in the $\mathrm{TiO}_{2}$ film is necessary to minimize the thickness of the overlayer, increase the penetration length of the spiro-MeOTAD and to optimally functionalize all the dye molecules in an ssDSC. In other words, for the solid electrolyte to achieve the same intimate contact with the dye molecules as a liquid electrolyte, the infiltration conditions must be engineered so that a more concentrated solution will enter the pores, either by altering the viscosity of the spiro$\mathrm{MeOTAD}$ solution and/or by altering the pore radii of the $\mathrm{TiO}_{2}$ film.

\section{Acknowledgments}

The authors kindly acknowledge Professor Dr. Rene Janssen (TU/e) for allowing us to work with their PIA setup. They are also kindly acknowledge Jan Kroon for helpful discussions. Thanks due to Esther Cobussen for evaporating the gold contacts and to Sjoerd Veenstra for providing the [70]PCBM. Thanks due to G. Boschloo for introducing us to their PIA set-up at Uppsala University. The funding for this work was provided by the Dutch Ministry of Economic Affairs. 


\section{References}

[1] P. Wang, B. Wenger, R. Humphry-Baker et al., "Charge separation and efficient light energy conversion in sensitized mesoscopic solar cells based on binary ionic liquids," Journal of the American Chemical Society, vol. 127, no. 18, pp. 68506856, 2005.

[2] P. Wang, S. M. Zakeeruddin, J. E. Moser, M. K. Nazeeruddin, T. Sekiguchi, and M. Grätzel, "A stable quasi-solid-state dyesensitized solar cell with an amphiphilic ruthenium sensitizer and polymer gel electrolyte," Nature Materials, vol. 2, no. 6, pp. 402-407, 2003.

[3] B. O’Regan and M. Grätzel, "A low-cost, high-efficiency solar cell based on dye-sensitized colloidal $\mathrm{TiO}_{2}$ films," Nature, vol. 353, pp. 737-740, 1991.

[4] E. Figgemeier and A. Hagfeldt, "Are dye-sensitized nanostructured solar cells stable? An overview of device testing and component analyses," International Journal of Photoenergy, vol. 6, no. 3, pp. 127-140, 2004.

[5] H. J. Snaith, A. J. Moule, C. Klein, K. Meerholz, R. H. Friend, and M. Grätzel, "Efficiency enhancements in solid-state hybrid solar cells via reduced charge recombination and increased light capture," Nano Letters, vol. 7, no. 11, pp. 3372-3376, 2007.

[6] U. Bach, Y. Tachibana, J. E. Moser et al., "Charge separation in solid-state dye-sensitized heterojunction solar cells," Journal of the American Chemical Society, vol. 121, no. 32, pp. 7445-7446, 1999.

[7] U. Bach, D. Lupo, P. Comte et al., "Solid-state dye-sensitized mesoporous $\mathrm{TiO}_{2}$ solar cells with high photon-to-electron conversion efficiencies," Nature, vol. 395, no. 6702, pp. 583585,1998

[8] Y. Shozo, Y. Youhai, and M. Kazuhiro, "Iodine/iodide-free dyesensitized solar cells," Accounts of Chemical Research, vol. 42, no. 11, pp. 1827-1838, 2009.

[9] H. J. Snaith and L. Schmidt-Mende, "Advances in liquidelectrolyte and solid-state dye-sensitized solar cells," Advanced Materials, vol. 19, no. 20, pp. 3187-3200, 2007.

[10] L. Schmidt-Mende and M. Grätzel, " $\mathrm{TiO}_{2}$ pore-filling and its effect on the efficiency of solid-state dye-sensitized solar cells," Thin Solid Films, vol. 500, no. 1-2, pp. 296-301, 2006.

[11] J. H. Yum, P. Chen, M. Grätzel, and M. K. Nazeeruddin, "Recent developments in solid-state dye-sensitized solar cells," ChemSusChem, vol. 1, no. 8-9, pp. 699-707, 2008.

[12] J. R. Durrant, S. A. Haque, and E. Palomares, "Towards optimisation of electron transfer processes in dye sensitised solar cells," Coordination Chemistry Reviews, vol. 248, no. 1314, pp. 1247-1257, 2004.

[13] H. Van't Spijker, B. O’Regan, and A. Goossens, “Quantitative study of electron losses in nanoporous anatase using transient absorption spectroscopy," Journal of Physical Chemistry B, vol. 105, no. 30, pp. 7220-7226, 2001.

[14] N. Kopidakis, K. D. Benkstein, J. van de Lagemaat, and A. J. Frank, "Transport-limited recombination of photocarriers in dye-sensitized nanocrystalline $\mathrm{TiO}_{2}$ solar cells," Journal of Physical Chemistry B, vol. 107, no. 41, pp. 11307-11315, 2003.

[15] J. Kroeze, N. Hirata, L. Schmidt-Mende et al., "Parameters influencing charge separation in solid-state dye-sensitized solar cells using novel hole conductors," Advanced Functional Materials, vol. 16, no. 14, pp. 1832-1836, 2006.

[16] M. Kunitz, "An empirical formula for the relation between viscosity of solution and volume of solute," Journal of General Physiology, vol. 9, no. 6, pp. 715-725, 1926.
[17] U. B. Cappel, E. A. Gibson, A. Hagfeldt, and G. Boschloo, "Dye regeneration by Spiro-MeOTAD in solid state dye-sensitized solar cells studied by photoinduced absorption spectroscopy and spectroelectrochemistry," Journal of Physical Chemistry C, vol. 113, no. 15, pp. 6275-6281, 2009.

[18] H. J. Snaith, R. Humphry-Baker, P. Chen, I. Cesar, S. M. Zakeeruddin, and M. Grätzel, "Charge collection and pore filling in solid-state dye-sensitized solar cells," Nanotechnology, vol. 19, no. 42, Article ID 424003, 2008.

[19] I.-K. Ding, N. Tétreault, J. Brillet et al., Adv. Funct. Mater., vol. 19 , pp. 2431-2436, 2009.

[20] E. W. Washburn, "The dynamics of capillary flow," Physical Review, vol. 17, no. 3, pp. 273-283, 1921.

[21] D. Patro, S. Bhattacharyya, and V. Jayaram, "Flow kinetics in porous ceramics: understanding with non-uniform capillary models," Journal of the American Ceramic Society, vol. 90, no. 10, pp. 3040-3046, 2007.

[22] N. Fries, K. Odic, M. Conrath, and M. Dreyer, "The effect of evaporation on the wicking of liquids into a metallic weave," Journal of Colloid and Interface Science, vol. 321, no. 1, pp. 118129, 2008.

[23] J. E. Moser, D. Noukakis, U. Bach et al., "Comment on "measurement of ultrafast photoinduced electron transfer from chemically anchored Ru-dye molecules into empty electronic states in a colloidal anatase $\mathrm{TiO}_{2}$ film"'” Journal of Physical Chemistry B, vol. 102, no. 18, pp. 3649-3650, 1998.

[24] G. Boschloo and D. Fitzmaurice, "Electron accumulation in nanostructured $\mathrm{TiO}_{2}$ (anatase) electrodes," Journal of Physical Chemistry B, vol. 103, no. 37, pp. 7860-7868, 1999.

[25] Y. Tachibana, J. E. Moser, M. Grätzel, D. R. Klug, and J. R. Durrant, "Subpicosecond interfacial charge separation in dyesensitized nanocrystalline titanium dioxide films," Journal of Physical Chemistry, vol. 100, no. 51, pp. 20056-20062, 1996.

[26] G. Boschloo and A. Hagfeldt, "Photoinduced absorption spectroscopy of dye-sensitized nanostructured $\mathrm{TiO}_{2}$," Chemical Physics Letters, vol. 370, no. 3-4, pp. 381-386, 2003.

[27] G. Boschloo and A. Hagfeldt, "Photoinduced absorption spectroscopy as a tool in the study of dye-sensitized solar cells," Inorganica Chimica Acta, vol. 361, no. 3, pp. 729-734, 2008.

[28] M. P. Struijk, High-spin through bond and space, Ph.D. thesis, TU Eindhoven, 2001, chapter 7.

[29] U. Bach, Solid-state dye-sensitized mesoporous $\mathrm{TiO}_{2}$ solar cells, Ph.D. thesis, EPFL Lausanne, 2000, chapter 4.

[30] D. Veldman, Charge generation in molecular materials, Ph.D. thesis, TU Eindhoven, 2008, chapter 8.

[31] The band gap and reduction potential of [70]PCBM are similar to those of C60-PCBM, $\left.{ }^{25}\right]$ hence the oxidation potential of is [70]PCBM must also be similar to that of $\operatorname{C60-PCBM}\left(E_{\mathrm{ox}}=+1.08 \mathrm{~V}\right.$ vs. $\left.\mathrm{Fc} / \mathrm{Fc}^{+}\right),\left[{ }^{23}\right]$ which is nearly $1 \mathrm{~V}$ higher than that of spiro-MeOTAD $\left(E_{\mathrm{ox}}=+0.118 \mathrm{~V}\right.$ vs. $\left.\left.\mathrm{Fc} / \mathrm{Fc}^{+}\right) .{ }^{22}\right]$ This allows efficient electron transfer from photoexcited [70]PCBM to spiro-MeOTAD.

[32] M. M. Wienk, J. M. Kroon, W. J. H. Verhees et al., "Efficient methano[70]fullerene/MDMO-PPV bulk heterojunction photovoltaic cells," Angewandte Chemie International Edition, vol. 42, no. 29, pp. 3371-3375, 2003.

[33] The absorption of the radical anion of [70]PCBM is likely to be obscured by the radical cation absorption of spiro-MeOTAD. This is also the case for MDMO-PPV:[70]PCBM blends. [25]. 


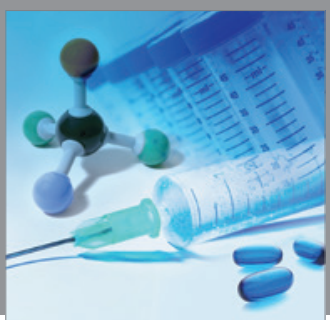

International Journal of

Medicinal Chemistry

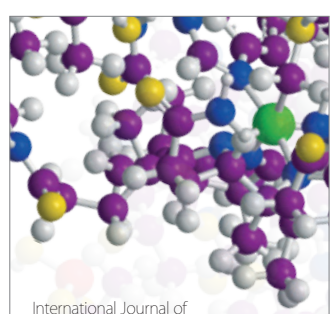

Carbohydrate Chemistry

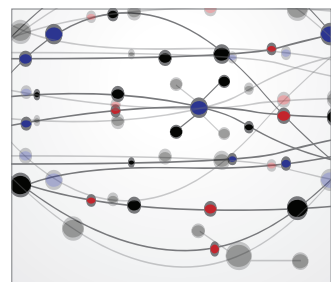

The Scientific World Journal
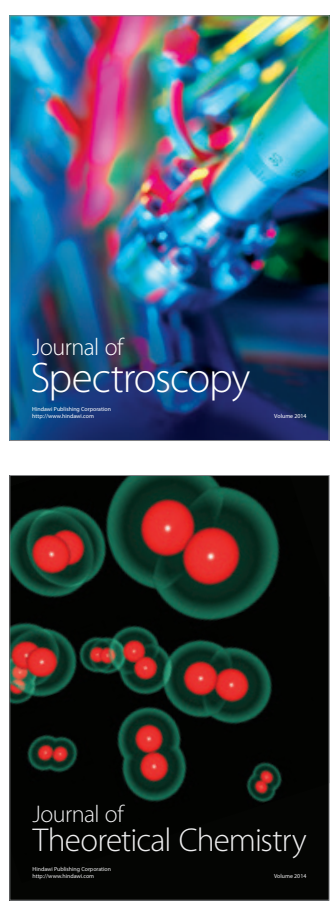
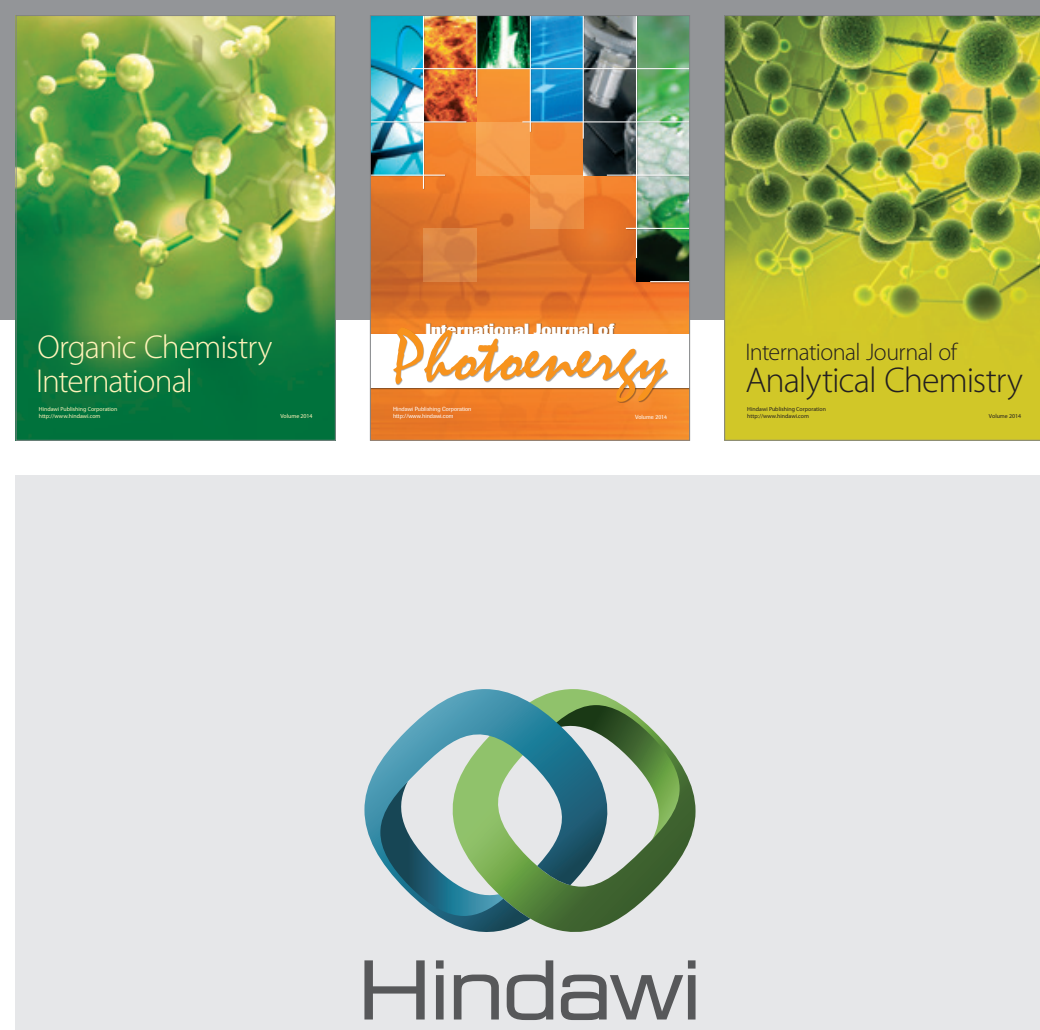

Submit your manuscripts at

http://www.hindawi.com
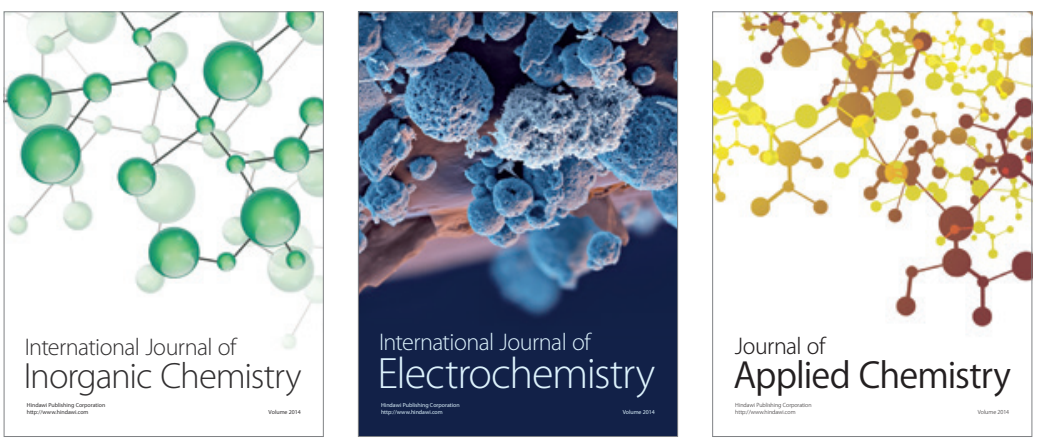

Journal of

Applied Chemistry
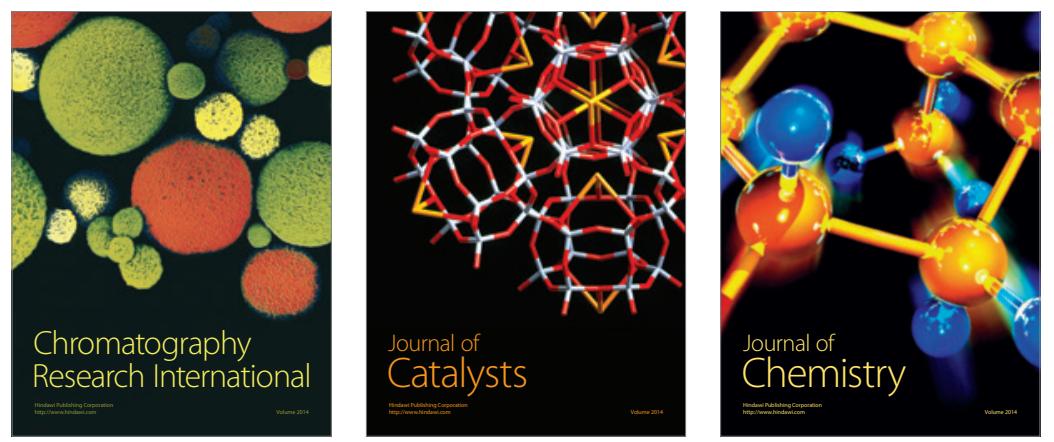
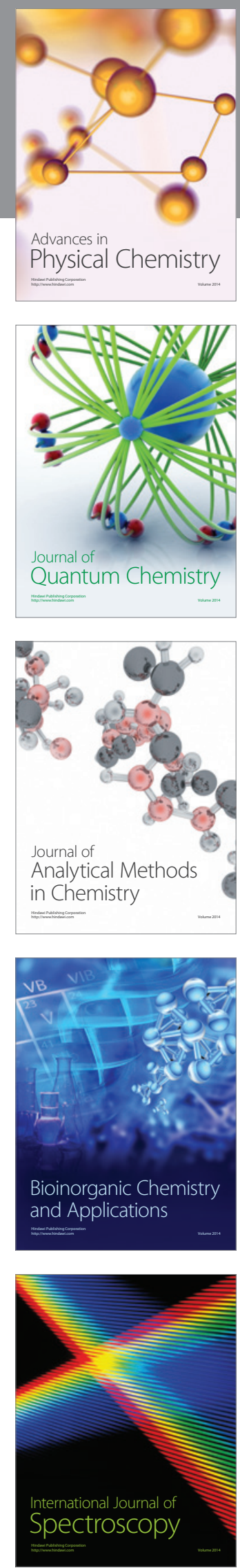